\title{
MONUMENTALIDAD Y PAISAJE EN LA PRODUCCIÓN DE FRONTERAS: EXPLORANDO PAISAJES NACIONALES/ISTAS DEL EXTREMO NORTE DE CHILE
}

\author{
MONUMENTALITY AND LANDSCAPE IN THE PRODUCTION OF BORDERS: \\ EXPLORING NATIONAL/IST LANDSCAPES IN THE NORTHERNMOST \\ REGION OF CHILE
}

Dante Angelo ${ }^{1}$

\begin{abstract}
El presente artículo analiza, mediante una mirada arqueológica, la construcción de la frontera moderna. Tomando como caso de estudio una sección de la frontera del actual norte chileno y lo que podría definirse como un "pequeño parche" en la inmensidad del desierto de Atacama, busco interrogar la relación entre paisaje y monumentalidad en la producción de las fronteras nacionales. Para tal efecto, empleo un marco metodológico y conceptual que explora algunos de los principios de la arqueología de paisajes, corriente que se ha popularizado en la arqueología de los Andes en las últimas décadas. A partir de este análisis se busca contribuir a debates sobre la modernidad,enfatizando como estos espacios marginales fueron centrales en la configuración de los espacios nacionales y constituyeron lo moderno desde la periferia.
\end{abstract}

Palabras claves: paisaje, monumentalidad, máquinas, andariveles, modernidad.

In this article, I archaeologically scrutinize the construction of modern frontiers. By considering a small section of the current Chilean northernmost border and a patch of the Atacama Desert territory, I interrogate the relationship between landscape and monumentality, used in the production of national borders. In order to accomplish my goal, I recourse to a conceptual and methodological framework, exploring and inquiring about some of the principles of landscape archaeology, atheoretical trend that gained relevance in the archaeology of the Andes in the last decades. Thus, by highlighting the role that these marginal settings had in the configuration of a national territory, I expect to contribute to the study of modernity and how it builds itself from the outskirts of the nation.

Key words: Landscape, monumentality, machines, cableways, modernity.

Mientras que los paisajes prehispánicos del mundo andino han sido extensivamente estudiados (Acuto 1999, 2005; Moore 1996; Troncoso 2006; Vitry 2003; entre otros), los paisajes históricos de los Andes, coloniales o republicanos, son comúnmente ignorados en estudios arqueológicos. La poca atención a paisajes históricos por parte de la arqueología andina, a mi parecer, responde a una sobrecarga valorativa de aspectos considerados como simbólicos en el universo ideacional de las sociedades prehispánicas que para muchos investigadores está imbuido en la construcción del paisaje andino. Así, los resabios de estos simbolismos, cuando son identificados, son considerados comúnmente como evidencias de continuidad cultural, casi de manera esencialista, de lo que se considera "lo andino". Además, los estudios de paisaje, relacionados generalmente a la idea de monumentalidad, enfatizan esa nostalgia colonialista que remarca el ideal de grandeza que los estados nación se esforzaron por promover.

La perspectiva descrita, común en los estudios de arqueología de paisajes, condujo a desviar la atención de la compleja, y muchas veces conflictiva, dinámica histórica en la que los paisajes se insertan. En este trabajo, mediante el análisis de la construcción de los paisajes de frontera, me interesa instrumentalizar la arqueología como una herramienta para entender las trayectorias de los procesos coloniales y neo-coloniales trazados en la construcción del discurso histórico de los estados nación. De esta forma, considero posible una aproximación histórica que permita desnudar algunos de los cimientos del capitalismo tardío (Harvey 2009) y enfatice el potencial de la arqueología para entender estos procesos de coexistencia histórica y sus entrelazamientos.

\section{Monumentalidad y Paisaje}

En su aclamada obra: La Producción del Espacio, refiriéndose a los monumentos, Lefebvre sostenía que estos "lograban esa belleza monumental porque parecían eternos, porque parecían haber escapado del tiempo. La monumentalidad -dice este autor-

\footnotetext{
1 Departamento de Antropología, Casilla 6-D, Universidad de Tarapacá. Arica, Chile. dangeloz@ gmail.com
} 
trasciende la muerte... tanto en apariencia como en la realidad, esta trascendencia está imbuida en lo monumental y su irreducibilidad" (Lefevre 1974:221). Citando a Lefebvre, Parker y Richards mencionan que "mediante las construcciones monumentales buscamos la encarnación física de un orden social eterno e imperescible, negando el cambio y transmutando 'el miedo al paso del tiempo y la ansiedad con respecto a la muerte en esplendor'..." (Lefebvre et al. 1994:4). Tomando esta premisa, diferentes autores remarcan la importancia de entender aquellos espacios habitados por sociedades del pasado como el producto de relaciones dinámicas y mutuamente constitutivas con un medio que no necesariamente es pasivo ni enteramente predecible (Johnson 2008; Tilley 1994).

A pesar de la relativamente reciente introducción del concepto paisaje en arqueología (Darvill 2008), la relación entre espacio social, territorio, monumentos y paisajes fue amplia y tempranamente reconocida por investigadores como Stukeley, Jefferson, Pitt Rivers y otros, quienes expresaron su interés por montículos funerarios, cercas, y otros como demarcadores territoriales. La monumentalidad, aspecto importante en la producción de paisajes y espacios han sido generalmente relacionados, implícita o explícitamente, a aspectos de monumentalidad en distintos periodos cronológicos de las sociedades andínas.

Aún cuando se demostró que las construcciones monumentales no dependen necesariamente de un poder centralizado y jerárquico (e.g. Erickson 1999, 2006) $)^{2}$, la monumentalidad ha sido tradicionalmente entendida en relación a la producción de ideologías y la estructuración de la complejidad social. A decir de Childe, por ejemplo, "[1]as construcciones públicas monumentales no solo distinguen las ciudades de los pueblos sino que también simbolizan la concentración de plusvalía social"' (Childe 1950:12, traducción propia). Estos supuestos son particularmente evidentes en la arqueología de los Andes Centrales y Sur-Centrales, donde las construcciones arquitectónicas presentes en sitios arqueológicos como Chavin de Huantar, Tiwanaku, Chan Chan y otros, han sido comúnmente caracterizadas como expresiones de poder funcionales a las elites de estas sociedades (Janusek 2004; Moore 1996)

No obstante, el concepto de monumentalidad es más que solo un tema de tamaño. Monumentalidad, nos dice James Osborne, más bien implica "[...] la relación entre personas y cosas que es constantemente renegociada entre el/los monumento(s) y la(s) persona(s) que conviven (experience) con dicho(s) monumento(s)" (Osborne 2014:3). El impresionante -o, podría decirse, monumental- poder simbólico que cargan imágenes de miniaturas, como es el caso de las figurinas neolíticas (Bailey 2005), y equivalentes más cercanas como las miniaturas encontradas en el sitio Tiwanaku (Ponce 1969; cf. Berenguer 2000) o las figurinas de la Isla
Pariti, en el Lago Titicaca (Korpisaari y Pärsinnen 2011; cf. Bubba y Albó 2010), parecen sustentar dicho planteamiento (Allen 2016). No obstante, si bien en este texto no haré referencias a figurinas o efigies de miniatura ni a lo que podría considerarse grandiosidad arquitectónica, me interesa remarcar aquellos aspectos de monumentalidad (sensu Osborne 2014) manifiestos en el proceso de estructurar las relaciones de las sociedades en las que ésta se presenta.

En ese sentido, el argumento de este trabajo se ajusta a la premisa de que ambos aspectos (paisaje y monumentalidad), se conjugan en la producción de fronteras modernas para poder otorgarle así su peso simbólico y político. Según Pascal Bardet, las fronteras son parte del "proceso de apropiación espacial que requiere de la introducción de límites, bordes y puntos focales, ya sean de tipo histórico, cultural, étnico, religioso, político o natural. De esa manera, los espacios sin forma o no identificados se convierten en territorios o lugares que son simbolizados por marcadores físicos (hitos) que se convierten en elementos esenciales de identificación" (Bardet 2012:1, traducción propia). Así, la definición de fronteras es por excelencia una construcción paisajística y, como espero mostrar en este texto a partir del caso histórico de la creación de fronteras nacionales en el norte chileno, usualmente implica la incorporación de elementos de monumentalidad.

A partir de estas consideraciones, mi abordaje a la relación entre monumentalidad y paisaje toma en cuenta precisamente la dinámica implícita en la construcción de experiencias en relación al paisaje, identidad y estructura social. En ese sentido, es importante remarcar que los paisajes no solamente reflejan pasivamente niveles o esquemas de organización socioeconómica en el espacio. En otras palabras: "el estudio del paisaje no puede limitarse solo al estudio del uso del suelo (organización de actividades económicas en el espacio)" (Rubertone 1989:51), sino que el paisaje deber ser entendido como una fuerza activa en la creación del orden social, su legitimación (e inclusive su cuestionamiento).

Siguiendo estas premisas, en la discusión, rescato dos conceptos recientemente explorados por el historiador Sergio González ('geosímbolo' y 'máquina')3. Estos conceptos resuenan con el argumento y análisis de este trabajo y que son posibles de seguir profundizando a partir de la mirada de la arqueología de paisajes aplicada a la frontera.

\section{Paisajes, Monumentos y Fronteras: Una Mirada a la Construcción Territorial Histórica}

Al inicio de este nuevo siglo, la construcción de las fronteras se hizo profundamente relevante a nivel global. La crisis de migrantes y refugiados desatada en 
Europa y, más recientemente en Estados Unidos, como producto de la crisis económico-política y los conflictos bélicos en el cercano oriente y otras regiones, ha generado inquietantes imágenes de "la frontera" que, de alguna forma u otra, se instalan en el imaginario político global. La construcción de fronteras está vinculada a la definición de aquello que queda adentro del espacio que estas contienen (la gente, en ese sentido, se convierte en "blancos móviles" de estos mecanismos); por esto, una vez más, es importante situar la atención de nuestros análisis en estos espacios y territorios fronterizos.

Las fronteras tienen como fin último el establecer la noción de orden y control sobre un territorio, pero sobre todo para definir un territorio en términos de su uniformidad (sensu DeLanda 2006); así, el caso de la creación de la frontera chileno-boliviana, establecida luego de la Guerra del Pacífico (1878-1883), ofrece un excelente caso de análisis de aquellos procesos que caracterizan la construcción de lo que actualmente entendemos como modernidad. Historiadores y antropólogos estudiaron este fenómeno a partir de la implementación de mecanismos de chilenización (proceso de reforzamiento identitario-nacionalista que Chile implementó en los territorios ganados), como el sistema educativo (Aguirre y Mondaca 2011) y las reconfiguraciones identitarias al interior de este territorio (González 1997). No obstante, si bien estudios de historia económica remarcan la importancia del desarrollo industrial en el norte chileno, la importancia empírica y dura de la materialidad de fronteras, particularmente en ese momento de la historia, ha sido poco estudiada. Esta situación plantea un interesante desafío para la arqueología, disciplina enfocada en el estudio de los restos materiales del pasado por excelencia.

A finales del siglo XIX, luego de la Guerra del Pacífico, el establecimiento de industrias que propulsaran actividades extractivas fue parte determinante de la consolidación del territorio chileno (Figura 1). En todo este procedimiento de territorialización, los procesos de industrialización marcaron la configuración y producción del paisaje desértico del actual norte de Chile, a modo de huellas en el entorno. Por tanto, planteo que la consolidación de poblados laborales y creación de centros industriales, como es el caso de las oficinas salitreras y azufreras constituidas a principios del siglo XX, formó parte de las estrategias de consolidación territorial y económica del Estado chileno en esta región. Este proceso fue mutuamente constitutivo con el establecimiento de fronteras, las cuales son exploradas tanto en términos de su conceptualización ideológica como de su materialización física.

Por lo anterior, el análisis de esta producción paisajística que aquí se presenta contribuye a la discusión y debates teóricos en torno a los procesos industriales que consolidaron el capitalismo emergente de principios del siglo XX (Orange 2012; Rubertone 1989), observado desde esta región del mundo. En base al estudio de la materialidad de los restos del pasado observados a través de los lentes de la arqueología, sostengo que la incorporación de nuevas tecnologías (maquinarias y mecanismos de poder) logró consolidar y hacer tangible la noción de frontera en estos confines instaurando un sentido de monumentalidad que fue instrumental a la territorialidad modernizante. La construcción discursiva de la frontera dependió marcadamente de la colosal presencia física de maquinarias, andamiajes, asentamientos y otros ensamblajes que domesticaron y "dieron vida" a un paisaje previamente concebido como agreste, desértico y abandonado 4 . Los casos de estudio en los que baso mi discusión están conectados entre sí, no necesariamente en términos de su cercanía o proximidad geográfica directa, sino por las conexiones históricas, económicas y políticas que se entrelazan en una matriz culturalmente compleja.

\section{El rol de la industrialización en la conformación del territorio del norte chileno}

En América del Sur, los procesos industriales empezaron a gestarse casi paralelamente a la conformación de los nuevos estados nación, luego de las guerras independentistas producidas a principios del siglo XIX. En Chile el proceso de industrialización es un tema en discusión ya que mientras algunos historiadores consideran que ésta había surgido solo posterior a la crisis mundial de 1929-1930 (Pinto 1959; Véliz 1963), otros enfatizan la necesidad de reconocer que este proceso ya estuvo inmerso tanto en las políticas de desarrollo económico como en la formación del imaginario social de Chile, desde mediados del 1800 (Ortega 1981; cf. De Vos 1999; Pérez 1893; Pinto y Ortega 1990). La industrialización del país inició su apertura al capitalismo global incentivando no solo la adopción de tecnologías sino promoviendo la creación del ethos nacional moderno. Esto se produjo mediante distintas estrategias de ingeniería social como la apertura de sus fronteras a migrantes europeos y facilitando la inversión de capitales extranjeros durante la primera mitad del siglo XIX (Bernedo 1999; Domeyko 1850; Pérez Rosales 1854; Soto 1998).

A finales de ese siglo, el establecimiento de industrias extractivas fue parte determinante de la constitución y consolidación territorial del norte chileno en períodos posteriores a la Guerra del Pacífico (De Vos 1999). No obstante, como observa acertadamente Sergio González (com. personal 2017), es importante tener en mente que no todas las denominadas oficinas funcionaron simultáneamente con maquinarias, sino que muchas de ellas mantuvieron un modo extractivo precario por mucho tiempo antes de la introducción de la tecnología Shanks o Guggenheim. Por esta razón, la construcción de vías férreas, poblados industriales 


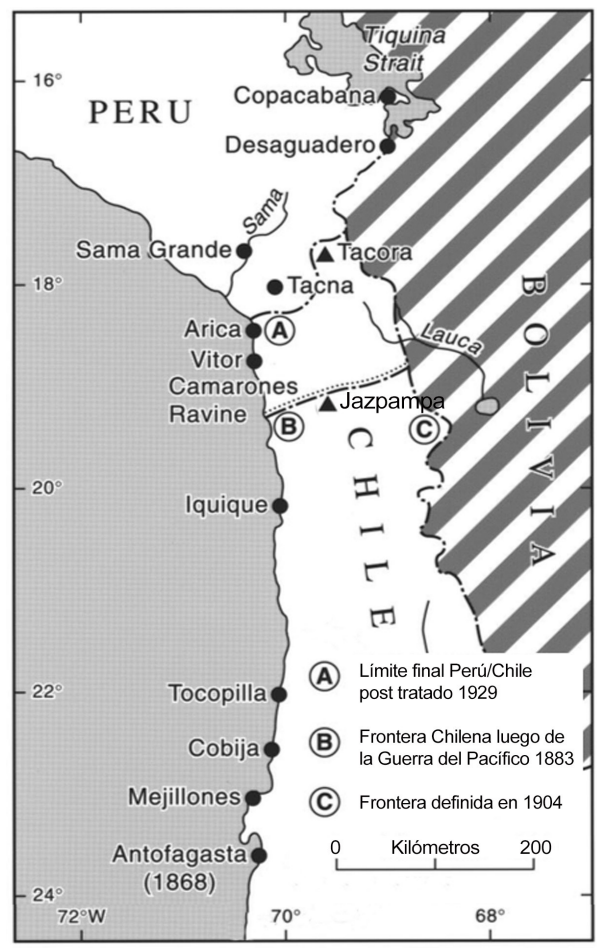

Figura 1. Modificaciones ocurridas en la frontera chileno-peruano-boliviana durante finales del siglo XIX e inicios del XX.

Changes in the Chile-Perú-Bolivia border by the end of the nineteenth and beginnings of the twentieth century.

(inserción de maquinarias y otros) y el mejoramiento de las rutas de transporte que se produjo principalmente en el valle central, a partir de la segunda mitad del siglo XIX, constituyen el demarcador más evidente del inicio del proceso de la industrialización en Chile (Ortega 1981). A partir de 1880, período de conflicto entre Chile y los aliados Perú y Bolivia, este proceso se intensifica y formaliza en el norte, mediante alianzas del Estado con capitales privados (principalmente extranjeros) a fin de establecer políticas de control territorial.

Por ese entonces, el recientemente instalado Estado chileno, proyectó a estos poblados industriales como elementos claves, no solo como parte de sus objetivos económicos, sino principalmente como el medio para domesticar el inhóspito territorio (y sus habitantes). A pesar de las diversas contribuciones que, desde disciplinas como la historia y la antropología (González 1997; Gónzalez y Ruz 2015; entre otros), se ha realizado para entender los fenómenos y procesos sociales y culturales que tomaron lugar luego del conflicto del Pacífico, la arqueología se ha mantenido alejada del tratamiento de estas temáticas. Este trabajo busca ser una contribución inicial al respecto.

\section{Mapeando la modernidad incipiente en el territorio anexado de Tarapacá}

La vasta extensión de sus zonas desérticas y la majestuosidad de las regiones de cordillera son dos aspectos que, relacionados entre sí de manera indisoluble, están presentes en el imaginario actual del norte chileno. A esto, históricamente se le fue añadiendo la identidad de la región minera, que impulsó el desarrollo nacional y fortaleció la imagen de Chile como país moderno. González afirma que: "El Norte Grande de Chile nació a la vida del país en el siglo diecinueve con las fronteras que conocemos actualmente, pero recién en el primer tercio del siglo veinte las consolidó tanto de facto como de jure, a través de la urbanización de su territorio como por Tratados Internacionales" (González 2009a:1911). Es decir, el interés por establecer control de estos importantes yacimientos mineros por el Estado chileno se hizo aún más evidente luego del conflicto armado con Bolivia y Perú; es entonces cuando Chile obtiene posesión de territorios que conformarían la región de Tarapacá e implementa una serie de estrategias para la chilenización de estos territorios y su gente (Cadiz 2013; Díaz et al. 2004; González 2002, 2006).

Continuando prácticas extractivas ya presentes en estos territorios desde mitades del siglo XIX, Chile incentiva la explotación de recursos como el salitre y el azufre en los territorios incorporados y define el proceso de industrialización de esta parte del país. La subsecuente adopción e incorporación de tecnología para los sistemas de explotación, como en el caso de las faenas salitreras y azufreras, se traduce en la adopción de ideas e instalación de maquinarias innovadoras que cambiarían para siempre la rutina de sus habitantes y el 
paisaje natural y social del norte (Bittmann y Alcaide 1984; Soto 1998; Vilches et al. 2008). La azufrera Tacora, situada a los pies del volcán del mismo nombre ${ }^{5}$, y la oficina salitrera Jazpampa son considerados como casos representativos de la construcción monumental de paisajes fronterizos. Establecidos a inicios del siglo XX, estos dos casos nos permiten introducirnos a la compleja producción de territorio a través de la reconfiguración paisajística de un espacio definido originalmente como vacío.

\section{Tacora: la frontera hecha de volcanes, andamiajes y cableados}

Con un área de más de 470 hectáreas, el Complejo Industrial Azufrero de Tacora (CIAT) fue un centro de explotación minera de importancia vital para el Estado Chileno (Thomson 2009; cf. Decreto 514 del Ministerio de Educación, Chile, 17-11-2015). Para fines de este trabajo, me enfocaré simplemente en el poblado de Aguas Calientes ${ }^{6}$, el poblado minero situado a los pies del Tacora establecido durante la década de 1920 y que, de acuerdo a González y Ruz (2015:145-148), fue constituido sobre territorios que la administración colonial reconocía como terrenos comunitarios ${ }^{7}$. Aguas Calientes está comprendido por tres áreas de actividades: Área 1) las oficinas y faenas de tratamiento en la base del volcán; Área 2) el campamento y viviendas de obreros, y Área 3) las faenas de altura y sistema de andariveles (esta última incluye el "sector de montaña y andariveles" descrito en el Decreto 514) (Figura 2). Estas áreas estaban interconectadas por los ramales del Ferrocarril Tacora, que a su vez se conectaba con la red del Ferrocarril Arica - La Paz (FCALP) en la estación de Villa Industrial (esta última estaba situada a más de $20 \mathrm{~km}$ de Aguas Calientes y fue excluida del presente análisis).

A principios del siglo $\mathrm{XX}$, la demanda de azufre por parte de la industria química y la fabricación de pólvora además de otros usos, como el refinamiento de minerales, se incrementó considerablemente (Pinto y Ortega 1990). Para la segunda mitad del siglo XIX, la producción de azufre excedía las 16 millones de toneladas, la cual era mayormente suplida por las minas de Sicilia (American Sulphur Mining Company 1871:5) y cuyo control de producción pasó luego a manos de capitales estadounidenses, a principios del siglo XX. Entonces, Chile promovió diversas expediciones en el territorio recientemente incorporado con resultados que llamaron la atención de capitales interesados en la explotación del azufre de alta calidad existente en esas regiones de la cordillera (Macchiavello 1935).

El interés suscitado por las minas de azufre fue tan alto que Chile decidió incluir un desvío en el trazado de la frontera en el Tratado de Lima de 1929, de modo que ésta incluya específicamente el Volcán Tacora dentro de los nuevos límites territoriales (Tratado
Chile-Perú 1929; cf. Sarwana 1969:229-230). Sin embargo, la explotación semi-industrial de azufre en Tacora, iniciada alrededor de 1888, no alcanzó niveles de producción óptimos, tanto en términos extractivos como de transporte, sino hasta después de 1913 cuando se habilitó el tramo de FCALP (Thomson 2009). Fue entonces cuando se iniciaron diferentes proyectos y trabajos para la instalación de maquinarias y tecnología que, para la década del 1930, caracterizarían el CIAT. Así, situados a más de $4.000 \mathrm{msm}$, la instalación de Aguas Calientes (y Villa Industrial), el sistema de ferrocarriles y, posteriormente los aparatos y maquinarias, fueron fundamentales en la definición de la frontera.

Si bien el azufre del volcán Tacora presentaba muchas ventajas, dada su alta calidad y la ubicación superficial de sus vetas, también planteaba serias dificultades para su explotación. Las condiciones climáticas severas y la elevación superior a los 4.000 msm limitaban la acción de obreros chilenos y la producción básicamente dependía de mano de obra indígena, proveniente del otro lado de las fronteras, quienes -al estar habituados a las condiciones de la region, se decía- podían resistir mejor las exigencias del trabajo ${ }^{8}$ (sensu Macchiavello 1935; cf. Díaz et al. 2016). La instalación de equipamento industrial fue vista como la alternativa viable para subsanar estos inconvenientes; además la instalación de la planta procesadora y otras maquinarias constituían, de por sí, un pronunciamiento oficial de soberanía por parte del Estado.

La planta de refinamiento situada en la ladera este del volcán Tacora (Área 1), con calderas de magnitud y una chimenea de $24 \mathrm{~m}$ de altura que funcionaba permanentemente, era claramente visible desde el otro lado de la frontera recientemente establecida (Figura 3); en ese mismo sector de la ladera del volcán, en el borde oriental del bofedal que forma el río Azufre, estaba la casa de pulpería y la oficina de administración. Al frente, situada en la vera occidental del río Azufre, marcador natural de la frontera, pero todavía en territorio chileno estaba el campamento que comprendía tres conjuntos de casas ordenadas linealmente de sur a norte (Área 2).

El primer conjunto, más al sur, presentaba dimensiones más pequeñas $(4 \times 4 \mathrm{~m})$ y se asemeja con el ordenamiento presente en oficinas salitreras, destinadas a albergar a trabajadores solteros. El segundo conjunto, compuesto por estructuras más amplias $(6 \times 3 \mathrm{~m})$ en su parte sur y otras más pequeñas $(3,5 \times 4 \mathrm{~m})$ en su parte norte, estaba al frente de la casa de pulpería, situada en las faldas del volcán al otro lado del bofedal. El conjunto final de habitaciones de más al norte, que incluía el área de mecánica del campamento presenta un espacio interno a modo de patio, cuya funcionalidad no pudo ser especificada en la prospección superficial. Finalmente, complementando este conjunto de actividad minera, esta el sistema de 


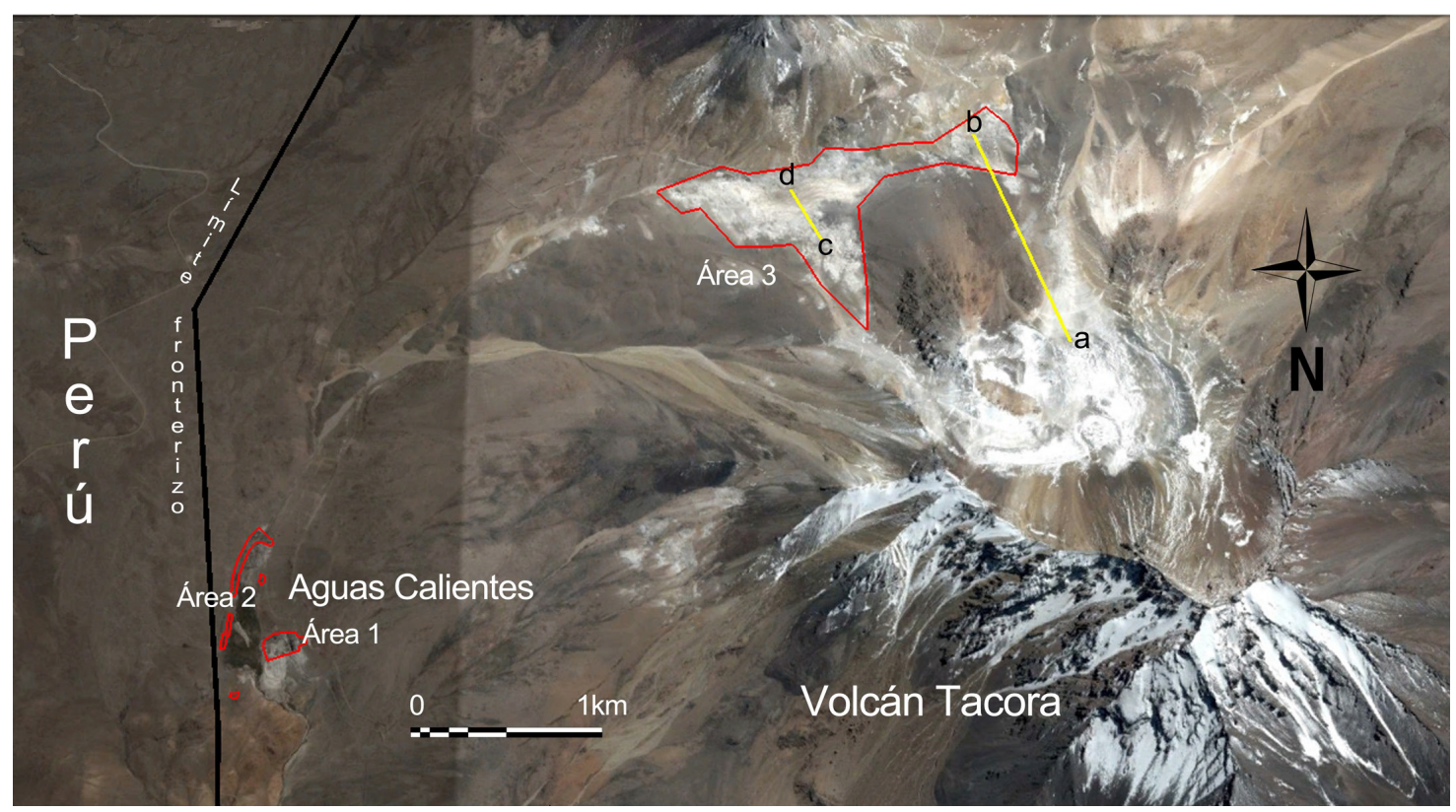

Figura 2. Imagen del sitio arqueológico Tacora, del Complejo Industrial Azufrero Tacora y las áreas que se mencionan en este trabajo tomada de Google Earth. Las áreas estan designadas con números y, al interior demarcado en amarillo, los tramos aún visibles del andarivel (a-b y c-d).

Google Earth image of the archaeological site of Tacora, showing the sectors mentioned in the text. The area are designated with numbers and, highlighted in yellow, the visible spans ( $a-b$ and $c-d$ ) of the cablew ays.

andariveles (Área 3) que había sido empleado con anterioridad en otros contextos mineros como las salitreras (como se verá más adelante); sin embargo, instalado en esta recóndita ladera durante la década de 1930 tenía una especial particularidad, la cual es descrita a continuación.

Emplazado en la ladera norte del volcán Tacora (Área 3), con poco más de un 1,5km de extensión, el sistema principal de andariveles permitía el transporte del azufre extraído en el cono inferior del volcán (3a) hasta las faldas del mismo (3b). Allí funcionaba el punto colector donde este material era puesto en trolleys (carros de mina) para su transporte a la refinería (Área 1) por medio del sistema interno de ferrocarril (Figura 2). Las catorce torres (3a-3b) resaltan en las montañas y son fácilmente divisables desde la distancia; incluso en la actualidad éstas permanecen incólumes, a pesar del abandono, como silenciosos guardianes del territorio (Figura 4). El sistema utilizado era de procedencia alemana (diseñados por la Pohlig AktienGesellshaft), y estaba montado sobre torres macizas de concreto y piedra, y sectores construidos con ladrillos ingleses Hannington (Figura 5). Las torres sostenían gruesas estructuras de metal y un sistema de poleas, cuyas dimensiones variaban entre 1 a $3 \mathrm{~m}$ de diámetro, dependiendo de su ubicación, asegurando el traslado de fuentes metálicas de entre 3 y más $\mathrm{m}^{3}$ de capacidad. Otro ramal del andarivel, más pequeño (casi $500 \mathrm{~m}$ de extensión reconocible arqueológicamente), se situaba en el punto de acopio de azufre sobre una explanada (3-c) a media altura del volcán, cerca de las fuentes de extracción, para conectarse con otro punto (3-d) que también conectaba con el ramal ferroviario.

Indudablemente, estas estructuras (tanto la planta procesadora de azufre como el sistema de andariveles), además de la presencia de las locomotoras y trenes serpenteando constantemente las laderas del volcán hacia la planta de refinamiento, tuvieron un gran impacto en la retina de los habitantes de ese alejado rincón de Chile. Aguas Calientes y sus áreas de actividad", imponían su presencia en un páramo distante de una geografía que estaba en proceso de consolidación, transformando el paisaje a través de construcciones que causaban un impacto modernizador en el mismo.

Así, se conjugaban performativamente dos aspectos relevantes de la configuración territorial: la noción de conquista de un territorio y la sensación de un espaciotiempo diferente instaurada entre sus habitantes; así, por ejemplo, la planta permanecía funcionando activamente incluso durante los meses de invierno, cuando las bajas temperaturas y las fuertes nevadas dificultaban la presencia humana e impedían el trabajo en las faenas de extracción. Además, tomando en cuenta que la ruta de bofedal del río Azufre constituyó históricamente un paso natural por el que se remontaba la cordillera, la presencia de este punto de actividad minera afirmaba también control territorial, vigilando específicamente aquellas rutas de arriería que, vigentes 


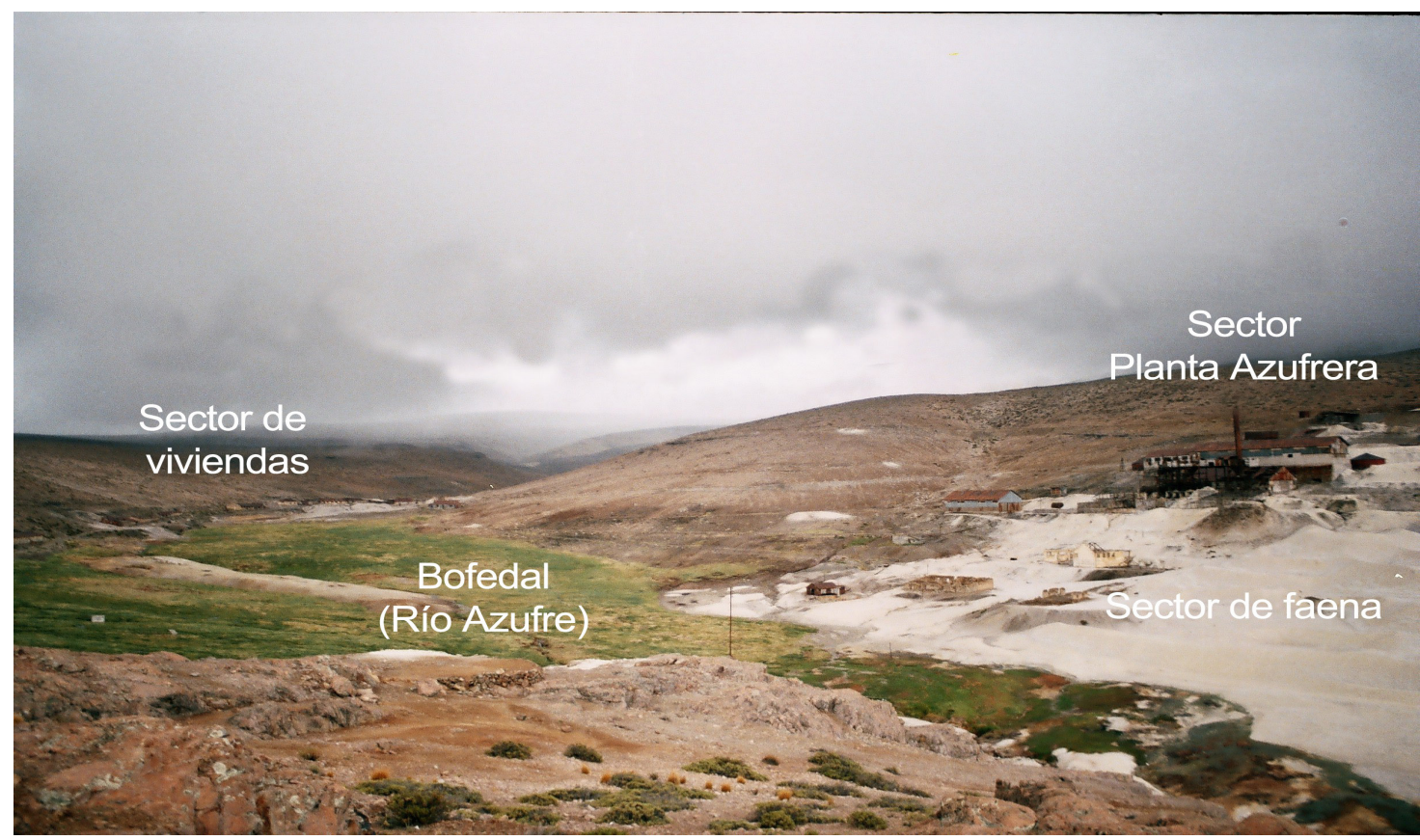

Figura 3. Planta azufrera de Tacora (planta de tratamiento a la derecha). El sector del bofedal divide el sector de viviendas, de la oficina y de pulpería.

Sulphur main works of Tacora (the refinery's chimney is at the right). The swamps of the Azufre River divide the living areas and the pulperia building.

desde tiempos de la Colonia (y, posiblemente mucho antes), se mantuvieron activas hasta mucho después de la demarcación fronteriza.

\section{Jazpampa ${ }^{10}$ : la punta de lanza tecnológica al norte}

La oficina salitrera Jazpampa fue uno de los puntos más septentrionales de explotación del salitre en el nuevo territorio que Chile. A diferencia de otros casos más emblemáticos, como es el caso de oficinas como Humberstone, Santa Laura y Sewell, que incluso forman parte de la lista de sitios de patrimonio mundial de la UNESCO, Jazpampa no ha sido objeto de mucha atención investigativa ${ }^{11}$. La escasa información existente señala que Jazpampa fue propiedad del mítico John T. North, conocido más tarde como el Rey del Salitre, quién la compró al Estado chileno luego de la Guerra del Pacífico (Boudat et al. 1889:51-53; Edmundson 2011; cf. González 2002:408).

Vinculada al ferrocarril y la línea telegráfica a Pisagua, Jazpampa empezó a funcionar en 1882 bajo administración de capitales ingleses (Edmundson 2011; González 2002:408) y, siguiendo a Agua Santa, probablemente fue una de las primeras oficinas donde el sistema Shanks fue instalado. Es importante remarcar para fines de este trabajo que el mapeo arqueológico de este sitio consideró principalmente Trinidad (la estación de trenes que comunicaba con Pisagua) y Jazpampa Bajo (la oficina salitrera), no como dos sitios distintos, sino como áreas separadas dentro de una unidad de análisis (Figura 6).

La primera, estaba situada en la ladera sur de la quebrada de Zapiga y la segunda sobre la meseta ubicada entre la mencionada quebrada y la quebrada de Tiliviche.

Jazpampa Bajo (Área 1) contaba con un sistema de trocha interna, posiblemente para trolleys, o quizás inclusive una locomotora pequeña, que les permitía transportar el salitre extraído de las tres áreas observadas hasta la base de la conexión del andarivel. Las vías del tren estaban armadas encima de terraplenes de 1,5 a $2 \mathrm{~m}$ de altura y $1,5 \mathrm{~m}$ de ancho, siguiendo la topografía (Figura 7), para conectar con una plataforma amplia donde se cargaban los carros del andarivel; la extensión total de las líneas de rieles es de $3.848 \mathrm{~m}$ adicionalmente la costra formada por la remosiones de tierra producidas en las áreas de extracción observables en la superficie de este sector septentrional de la pampa del Tamarugal, tiene un estimado de casi 100 ha.

Como para el caso de Tacora, el andarivel de 2 km de largo conectaba este campamento y área de faena (Área 1), desde donde se cargaba el salitre, a la estación de Triinidad situada en la cima de la ladera (Área 2), para trasladarlo luego al puerto de Pisagua. Jazpampa Alto, la oficina más próxima, no solo era el punto que conectaba la región más nortina del nuevo territorio, sino también la oficina de telégrafo. Ambos servicios habían sido instalados en períodos pre-Guerra del 


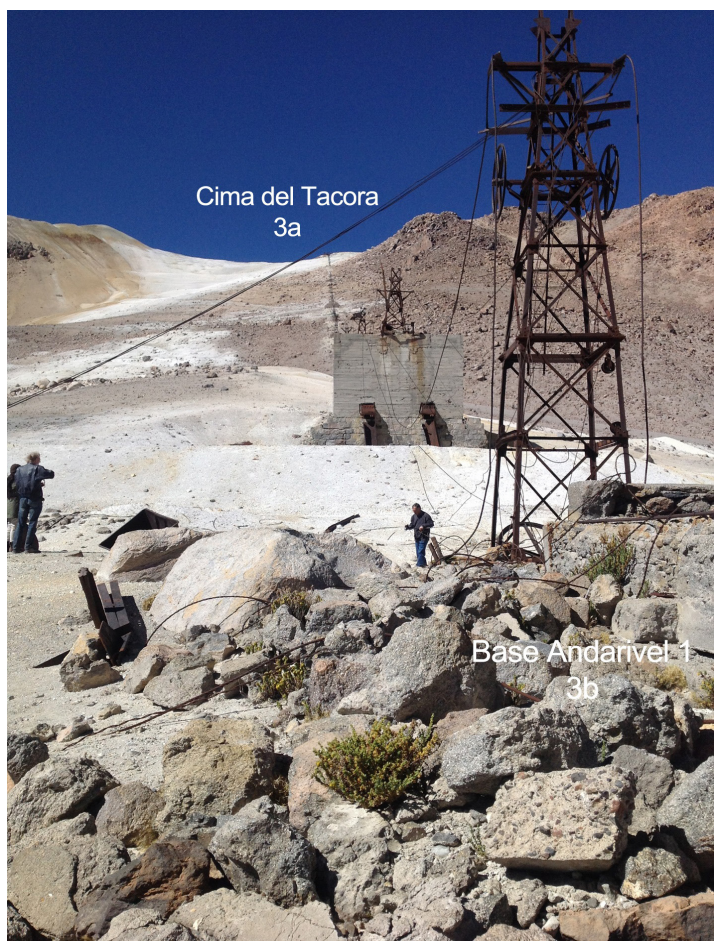

Figura 4. Vista norte-sur del andarivel 1 en el sector norte del Volcán Tacora. Nótese la línea de cableado que se extiende hasta la cima del Tacora y, en una plataforma superior, la torre de acopio con su sistema de descarga.

The cableway towers, looking from north to south towards the peak of the Tacora Volcano. Observe the cabled wires extended to the top of the Tacora and, in a upper platform, the deposit and loading system for the caliche.

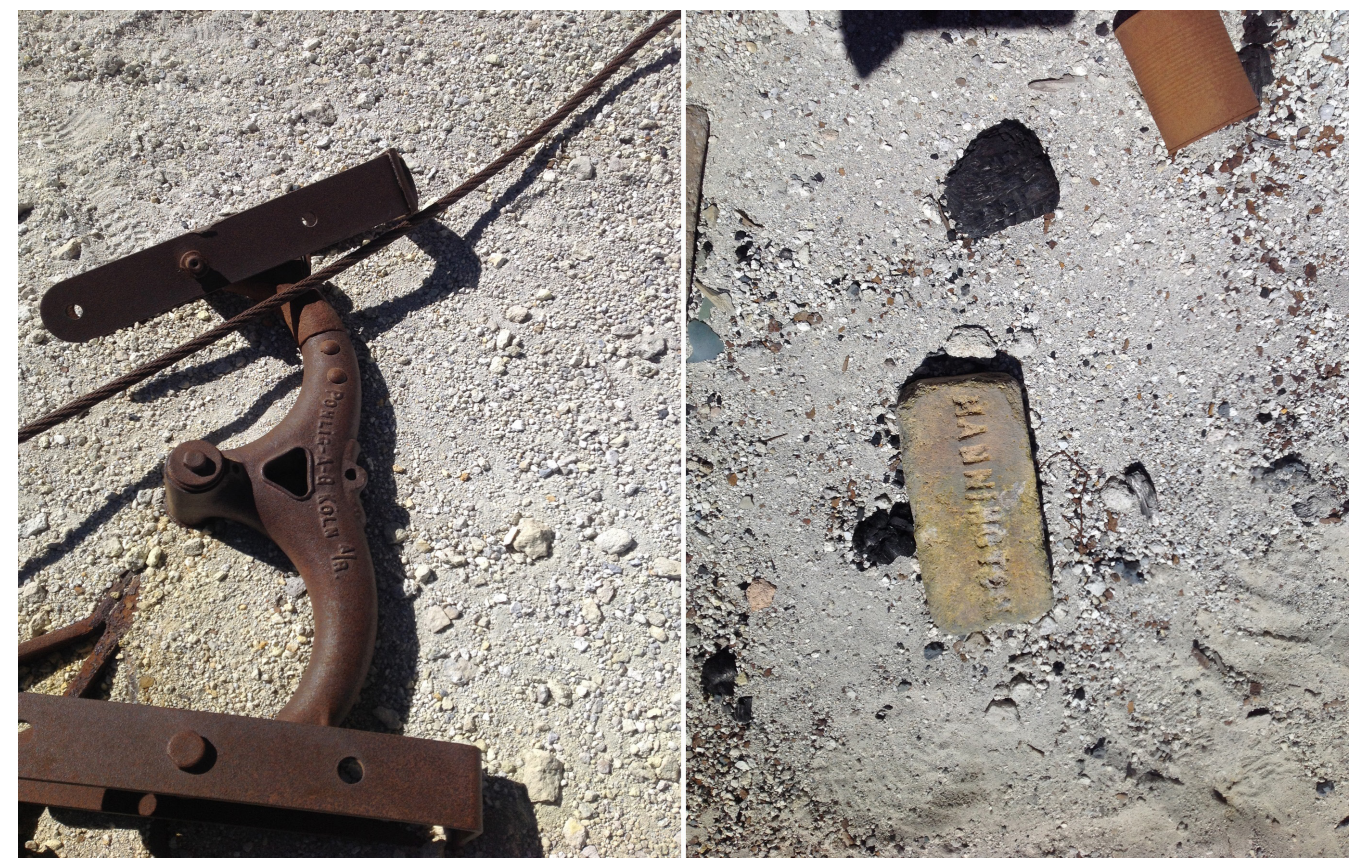

Figura 5. A la izquierda, restos de soporte del andarivel marca Pohlig, de fabricación alemana.

A la derecha: ladrillo Hannington, de fabricación inglesa.

At left, remains of the Pohlig cableway (made in Germany); at right, a Hannington brick (made in England). 
Pacífico y eran cruciales para poder comunicar estos apartados territorios con el resto del territorio nacional. Claramente, la importancia estratégica del lugar es evidente en el Boletín de la Guerra del Pacífico, en el que se remarca la importancia de este sitio para el ejército chileno cuando, luego de la toma de Pisagua, éste se apoderara de esta salitrera para abastecerse de agua antes de la batalla de Dolores (Chile 1979:439).

La magnitud de las obras y monumentalidad de la maquinaria empleada en el establecimiento de estos centros extractivos, indudablemente, tuvo un rol fundamental en la construcción del ideario de país. Es necesario recordar que la noción de aislamiento del mundo civilizado fue un discurso poderoso al momento de pensar la incorporación de lo que actualmente se conoce como el norte chileno. Esto es evidente en el párrafo siguiente, tomado de los Anales del Instituto de Ingenieros de Chile:

Las condiciones geográficas del país, nuestra remota situación en el mundo civilizado, la dificultad de estar al corriente de los adelantos científicos, la necesidad de proveerse de obras de indisputable mérito, están en pugna con la vida que está obligado a llevar un hombre de nuestra profesión: y más que todo, y con el aislamiento en que vivimos, cuando se quiere pagar un tributo al tiempo y asimilar nuevos conocimientos" (Anales del Instituto de Ingenieros de Chile 2011:5, énfasis propio).

Claramente, si estaeralamiradacomopaís, para lograrel anexamientoefectivodelnorte,elconfín aúnmásapartado de la geografía nacional, era necesario incorporarlo al ideal de un territorio mediante la presencia tangible de una estructura estatal moderna y sujetarlo a una grilla mayor. A esto se sumaba el discurso de estancamiento tecnológico que denostaba las condiciones de trabajo e incapacidad productiva de los empresarios peruanos (González 2012). La monumentalidad producida por las actividades y maquinarias empleadas en la extracción, almacenamiento, tratamiento y transporte de salitre en esta oficina salitrera, forma una especie de "puente" con lo civilizado y moderno. Las huellas y evidencias plasmadas en la instalación de estas maquinarias, demarcadas ahora por la ausencia de durmientes que soportaban los rieles de tren en Jazpampa (Figura 8) o la línea oscura que marca la trayectoria de salitre, polvora y otros materiales entre ambas áreas (Jazpampa Bajo y Trinidad), son aún claramente apreciables en el paisaje (Figura 9).

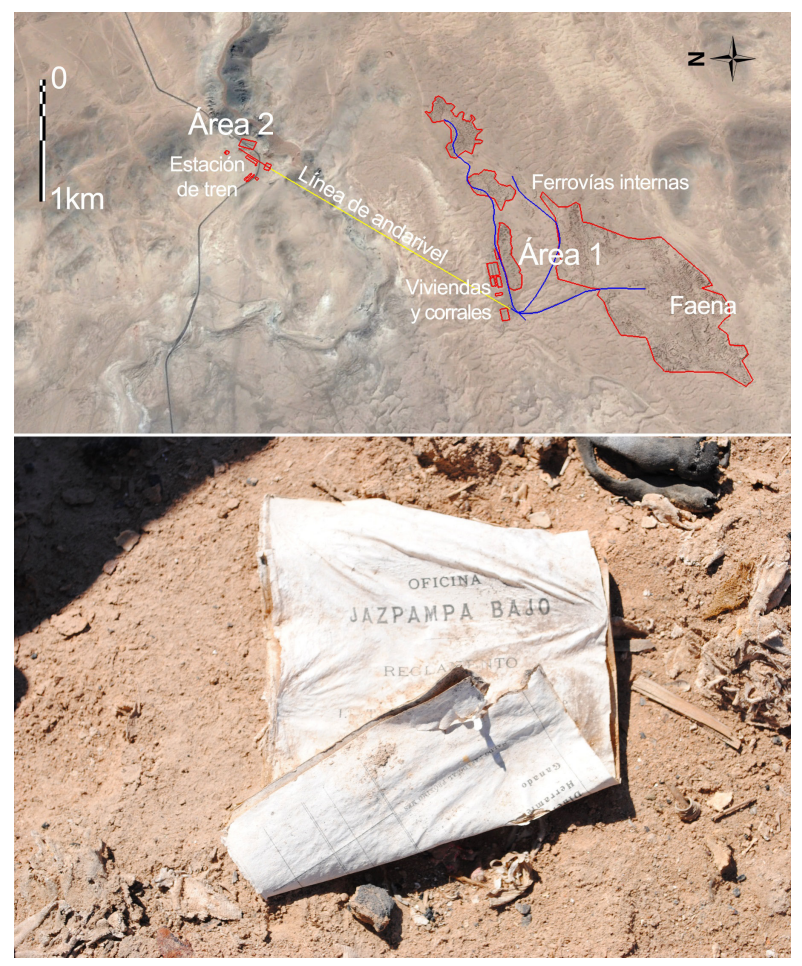

Figura 6. Imagen del sitio arqueológico Jazpampa, delimitando los sectores mencionados en este trabajo (tomada de Google Earth). En la parte inferior, restos de documentos de la oficina Jazpampa Bajo, registrados en el sector de basural durante la prospección.

Figure 2. Google Earth image of the archaeological site of Jazpampa, showing the sectors mentioned. Below, remains of official documents of the saltpeter works of Jazpampa, recorded during the surveying of the site. 
Si bien el tratamiento de la vida al interior de los campamentos excede los objetivos de este trabajo y seran desarrollados en otro espacio, desde el análisis espacial y de paisajes, es posible afirmar que la organización de los campamentos también reflejaba aspectos socio-estructurales, activando jerarquías y ordenes (cf. Rees et al. 2007), las cuales se conjugaban con un paisaje dominado por la monumentalidad de las máquinas. Así por ejemplo, González cita un poema de finales del siglo XIX, que dice: "Allá a lo lejos, álzase gigante (especie de obelisco en el desierto) robusto tubo de columna humeante que invita al trabajo al gran concierto" (González 2005:116), el cual complementa con un comentario de pie de página donde afirma:

"Aún hoy la vieja chimenea de la oficina Santa Laura, que inspirara una hermosa canción, cuyo autor fue Jorge Iturra, asombra al verla desde la distancia con su imponente tubo como si fuera un obelisco" (González 2005:116, nota 11). Estas palabras evidencian cómo la percepción de estas enormes maquinarias se reflejaban, y continúan haciéndolo, en el imaginario de las personas.

Como muchos autores han mencionado, el proceso de chilenización consistía principalmente en la transformación de aquellas personas indígenas y de nacionalidades distintas en sujetos nacionales y modernos. La máquina (y la tecnología), no solo ofreció eficiencia, sino también logró "desplazar la indianidad" de aquellos trabajadores que resistían las condiciones de altura (o calor agobiante del desierto), o asimilar otras nacionalidades de migrantes, para convertirlos en obreros y chilenos. En ese sentido, el despliegue performativo que este paisaje industrializado(r) presentaba y el proceso de asimilación (chilenizador) que desempeñaba estaba orientado a un tipo de población en específico, conformado principalmente por población indígena $\mathrm{y}$, en menor grado, a una población extranjera.

Además, observando el paisaje arqueológico de estos asentamientos industriales, se hace evidente que la monumentalidad de sus equipos, la celebrada precisión y eficiencia de la máquina y la disposición de viviendas está configurada para producir el individuo moderno y especializado (loncheros, barreteros, cateadores, carreteros, canchadores, y otros). Por tanto, el tema de las escalas que se movilizan y activan, algunas simultáneamente, es importante dado que no solo se trata de manejo de paisajes locales (y sus habitantes), sino que él mismo permite entrever el portento de los objetivos económicos imperiales/coloniales desplegados a escala global.

Indudablemente, estas presencias y modificaciones en el espacio, previamente inerte (según el discurso oficial), fueron cruciales para movilizar el efecto

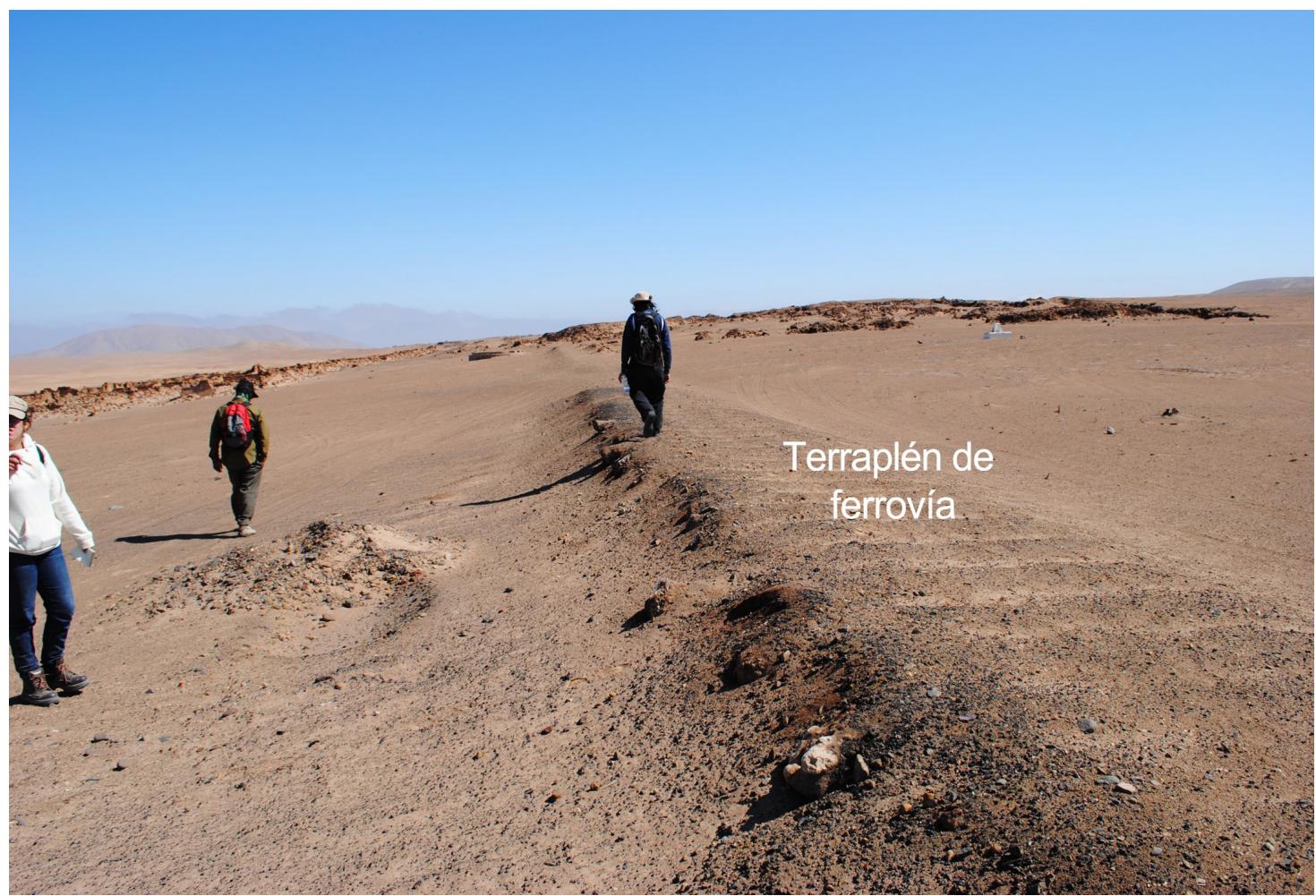

Figura 7. Terraplenes del tren de carga, al interior del sitio Jazpampa Bajo.

Embankments made to carry the in-site railroads in Jazpampa Bajo. 
de frontera y establecer el sentido de experiencia compartida en términos de espacio-tiempo. La producción de este espacio fronterizo tuvo así un efecto ordenador que no solamente se manifestó en términos espaciales. Como todo proceso de territorialización este ordenamiento principalmente buscó internalizarse en los habitantes de este nuevo territorio, formando así una nueva identidad basada en esta experiencia de habitar y compartir estos recónditos territorios con manifestaciones heterotópicas presentes en el paisaje.

\section{Discusión}

La producción de paisajes y fronteras ha caracterizado no solamente procesos de crecimiento demográfico, sino principalmente la evolución de estructuras y formaciones sociales. La arqueología de paisajes permite considerar la monumentalidad característica de los proyectos y paisajes asociados a procesos industriales (Beaudry y Mrozowski 2001; Cowie 2011; Given 2005; McGuire 1991), como uno de los elementos centrales de este trabajo. La arqueología de paisajes, además, ha sido particularmente efectiva en el estudio de aquellos componentes materiales de lugar (place), identidad y poder (Branton 2009).

El escrutinio arqueológico de la creación del territorio y frontera del actual norte chileno ofrece la oportunidad de historizar el proceso de inserción de formas y medios de tecnología que, complementando aquellos proyectos ideológicos, definieron la instauración y consolidación del capitalismo en esta parte del mundo. Ciertamente estas transformaciones territoriales no se producen por arte de magia o un efecto mágico atribuible a las máquinas ${ }^{12}$, sino que es mediante un proceso complejo de re-significación que produce un paisaje nuevo y moderno. Este proceso de construcción paisajística, que ocurre casi literalmente sobre un andamiaje tecnológico y que impone nuevas prácticas y usos en la matriz social de sus habitantes, es suceptible de ser observado en su materialidad. Así, la mirada arqueológica del paisaje brinda la posibilidad de analizar precisamente aquellos procesos de territorialización definidos por aspectos intrínsecos de la materialidad fronteriza, vinculados a la producción del paisaje y sus habitantes.

Lacreación de fronteras lleva implícita la formación o demarcación de algo que divide y diferencia y el control de aquello que contiene. Alejandro Grimson, en un ejercicio analítico, equipara los conceptos de cultura y frontera. Según él, la propia noción de 'cultura' de la antropología fue creadora de fronteras. De hecho una teoría de la frontera es una teoría de la cultura. Concebir la cultura como un todo integrado de costumbres, creencias y prácticas o como significados compartidos por una comunidad implica necesariamente delimitar con precisión conjuntos humanos (Grimson 2004:14).

En ese sentido, la incorporación de nuevas tecnologías y medios de producción en actividades extractivas no solo estaba orientada a demarcar diferencias territoriales entre estados soberanos, sino principalmente a evidenciar la transición hacia un estadio moderno: la industrialización, estableciendo mecanismos y tecnologías de control de aquello concebido como previamente arbitrario y natural.

Para el caso de Tacora, Thomson (2009) sugiere que el interés por la explotación del azufre declinó considerablemente luego de la Primera Guerra Mundial, afectando a estos centros mineros; indudablemente, éste y otros contextos y ritmos globales, como la crisis de la década de 1920, también impactaron a las salitreras. De ser así, la pregunta que surge es: ¿por qué al Estado chileno le interesó la instalación de este tipo de plantas de tratamiento y maquinaria minera en estos espacios inhóspitos, incluso aún durante tiempos de la crisis económica mundial? Sostengo que, si bien la importancia económica que tenían los yacimientos de recursos diversos (cobre, azufre, salitre y otros) es innegable, lo que realmente estaba en juego en este proceso de instalación de asentamientos y maquinarias en el medio del desierto más seco del mundo era la articulación de un discurso específico: el de la modernidad, al que se adherían otros más funcionales, como identidad y nacionalismo.

La importancia geopolítica de este apartado rincón, caracterizado por volcanes nevados y condiciones extremas (más de $4.000 \mathrm{msm}$ ), o territorios desérticos, rebasaba aquellos aspectos únicamente económicos atribuidos como fuentes de azufre o salitre. Además de la importancia económica de estos puntos de la geografía andina la ocupación del volcán Tacora y el extenso desierto de Atacama formaba parte de los objetivos de re-territorializar este espacio. Indudablemente, la configuración paisajística, tanto de aquella definida por la cadena montañosa de Los Andes como la de otros espacios del paisaje como era el caso del "descampado de Atacama", fue efectivamente utilizada en la construcción de las fronteras nacionales modernas.

Siguiendo el caso de estudio de la construcción de la frontera e identidad nacional mexicana de finales del siglo XIX, González (2009a:28) señala que las montañas y otros rasgos naturales de la geografía habrían tenido una relevancia central en la definición de fronteras modernas y sugiere, además, que dicha importancia estaría asociada al sistema ritual (apachetas) del mundo andino previamente vigente. Estos rasgos geográficos (volcanes y cadenas montañosas) son interpretados como geosímbolos ${ }^{13}$, los cuales habrían actuado como demarcadores espaciales que dieron sentido al territorio y su ordenamiento fronterizo. A pesar de las limitaciones del concepto, i.e.: observado principalmente en relación a aspectos de la geografía, González propone también caracterizar como geosímbolos a ciudades fronterizas (como Arica, Iquique y Antofagasta), en tanto que estas generaban procesos urbanos relacionados con el fortalecimiento 


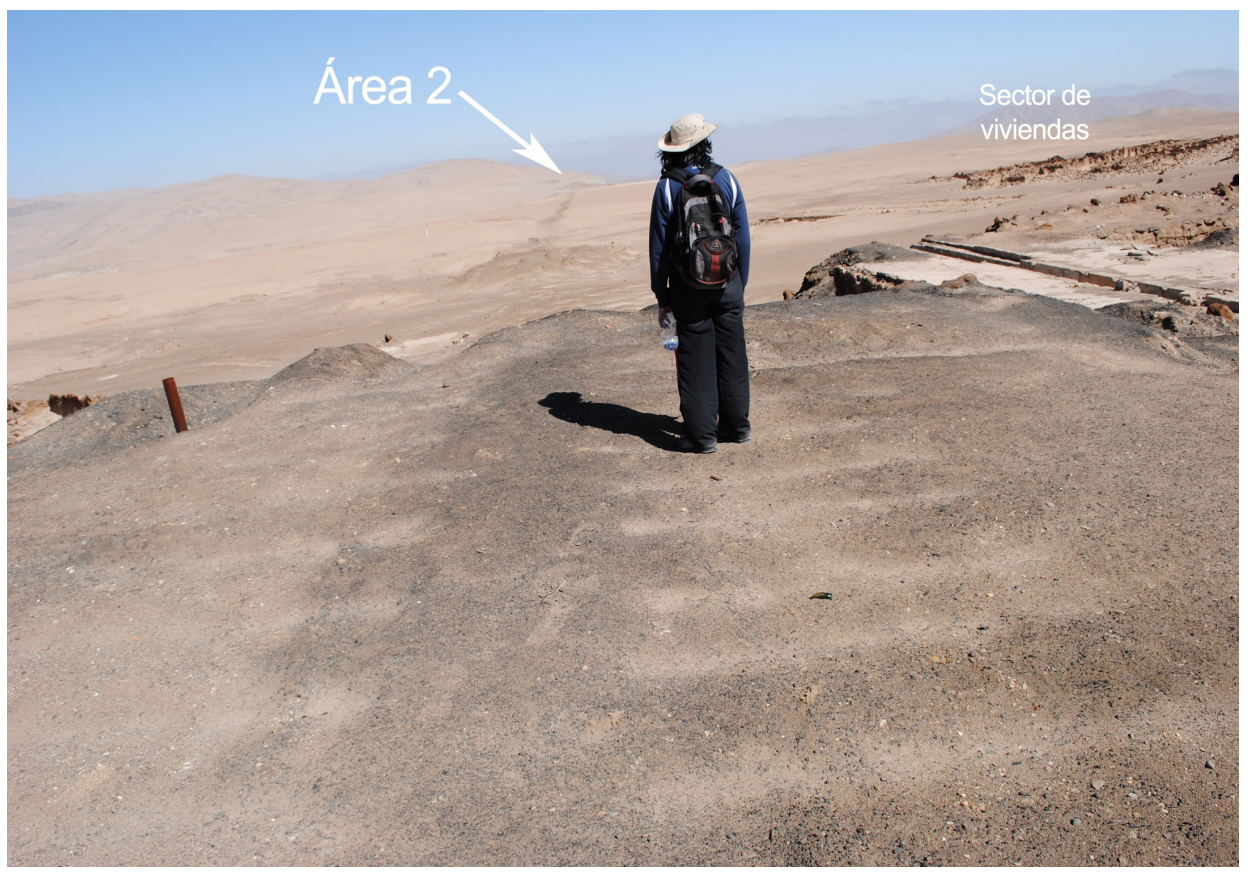

Figura 8. Antigua plataforma de descarga en Jazpampa (Área 2). Nótese la marcada ausencia de los durmientes que sostenían las rieles y, casi en la esquina superior derecha de la imagen, el sector de viviendas del campamento.

Old loading platform in Jazpampa Bajo (Area 2). Observe the clear absence of the sleepers that once held the rails and, at the upper right of the image, the houses sector.

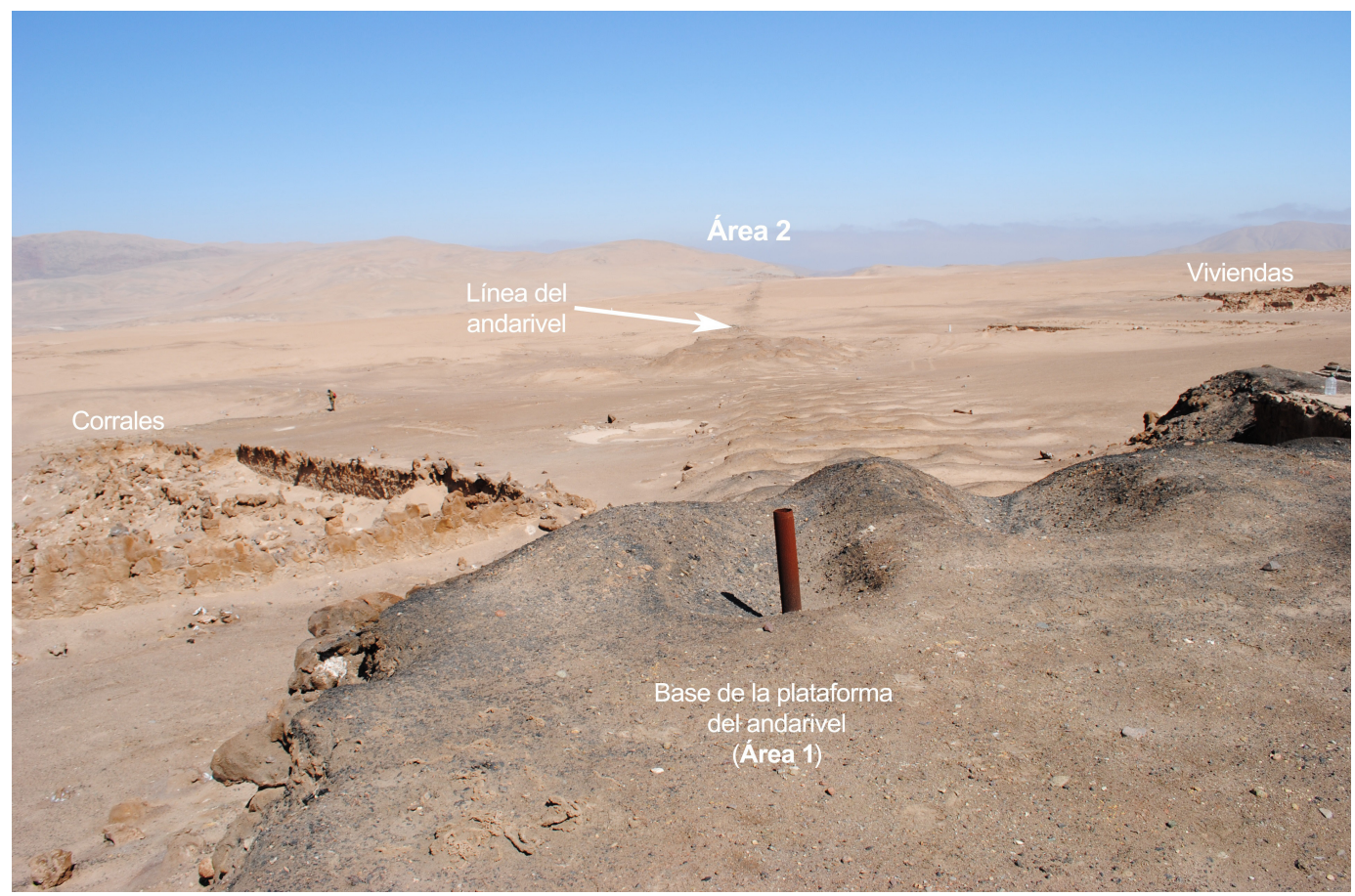

Figura 9. Línea dejada por los vestigios de transporte de mineral por el andarivel. A la izquierda de la imagen, restos del área de corrales. A la derecha, más a lo lejos, el campamento y las viviendas de Jazpampa Bajo (Área 2).

A line of mineral debris left demarcate the trajectory once followed by the cableway for the transportation of saltpeter, gun powder and other materials from Jazpampa Bajo to Jazpampa Alto, the train station; at the far right, the sector of houses (Area 2). 
de procesos identitarios (González 2009a). Sin embargo, a partir de un análisis arqueológico de los paisajes de frontera, es posible argumentar que estos rasgos geográficos no fueron suficientes por sí solos.

Basado en una perspectiva Heiddegeriana, González (2005) propone también entender la industria salitrera y su tecnología como una máquina que habría impactado el paisaje de la pampa. Esta propuesta, si bien exploratoria, según sus propias palabras (González (2005:115), constituye un intento valioso para entender la importancia de la materialidad que constituyó el proceso de industrialización. Si consideramos, siguiendo a Gloria Anzaldúa, que la frontera es "un lugar vago e indeterminado creado por residuos emocionales de un límite antinatural, en constante estado de transición" (Anzaldua 1987:3, traducción propia), es posible afirmar que la producción de estos nuevos territorios dependió significativamente de los paisajes creados por la industrialización. De igual manera, desde una perspectiva más arqueológica, es importante extender el concepto de la máquina empleado por González para, siguiendo a Deleuze y Guattari (1987), entender el rol elemental de las máquinas y tecnología en los procesos de deterritorialización y re-territorialización. Es igualmente evidente que estos procesos implicaron efectos perniciosos en aspectos identitarios relacionados a territorios previamente existentes a fin de articular la proyección de un nuevo sujeto, moderno y nacional.

La explotación minera de inicios del siglo XX ofreció el marco necesario para la expansión territorial y consolidación económica-legal del Estado chileno en la región. La instalación de asentamientos mineros y salitreros en medio del desierto, constituyó uno de los mecanismos más importantes en la ocupación y configuración de nuevos territorios y sus habitantes. La erección de instalaciones monumentales, que caracterizaban a las redes de trenes, andariveles, chimeneas, oficinas de maestranza y otros espacios de actividad industrial, formaban esos "otros espacios" que Foucault (1986) definió como heterotopias, que actuaban como fuerzas que irrumpen y distorsionan un orden visual previo, y toman posesión de él. Las fronteras, en este caso, funcionan creando heterotopias y heterocronismos que se yuxtaponen drásticamente con los entornos "naturales extremos" (desierto y cordillera) en los que se emplazan; así, estas presencias monumentales y su escala exagerada generan un "otro espacio" que rompe con el espacio-tiempo tradicional y se configuran como la antesala de la modernidad en estos remotos confines geográficos.

De esta forma, la industrialización actuaba como un efectivo instrumento en el establecimiento de los propósitos subyacentes - asimilación cultural de la población indígena y formación del "obrero" como sujeto nacional- implícitos en la política de chilenización del territorio y la población del norte.
Al igual que en Tacora, la imposición del nuevo sistema de asentamientos en el desierto de Atacama, respondía claramente a los objetivos de formación de población que se desempeñe acorde a la lógica expresa de la industria y modernidad. El hecho de que estos paisajes extremos estén coronados con redes de más de mil metros lineales de andariveles conectados a redes ferroviarias productivas, creando espectáculos heterotópicos, sugiere que más allá del uso industrial, estas instalaciones representan ejemplarmente los ideales de modernidad que el Estado chileno quería impulsar e "improntar" en su nuevo territorio. A pesar de la lejanía del mundo civilizado, las redes establecidas por el cableado entretejían también la conexión con un mundo diferente y buscaban la articulación de una identidad diferente.

\section{A Modo de Conclusiones}

Uno de los aspectos más importantes de los monumentos (del latin monumentum y monere) tiene que ver con el aspecto conmemorativo que estos tienen, aunque esta "fuerza activa" no se habilita por sí sola, sino, que generalmente es reconocida a partir de identificar aspectos relacionales de contingencia histórica (Osborne 2014). La construcción del ideal de comunidad cultural, entiéndase nacionalismo chileno en el caso que nos ocupa, fue constituida simultánea y complementariamente a la articulación territorial y de sus fronteras físicas, y ésto dependió ampliamente de introducir un paisaje tecnologizado y monumental.

El desarrollo industrial ha sido uno de los temas de importancia crucial para historiadores interesados principalmente en aspectos estructurales relacionados a la organización social e institucionalización de los procesos productivos, la organización del mercado, y los procesos políticos promovidos por intereses económicos que derivaron en estrategias gubernamentales de control de territorios y recursos (Barnes y Feldman 1980; Rueschemeyer et al. 1992). Poblados como Tacora y Jazpampa dan fe de procesos industriales que por mucho tiempo constituyeron la columna vertebral de la economía nacional a partir de las conexiones comerciales que la producción minera de estos asentamientos generó. La consolidación de la modernidad y sus sociedades tiene que ver precisamente con el fortalecimiento de algunas de las características distintivas del capitalismo como un sistema económico que se instaura rápidamente a escala global.

No obstante, aunque pareciera ser que la implementación de modelos y mentalidad capitalista implícita en la instauración de estos elementos paisajísticos anuló/erradicó aquellos aspectos simbólicos previamente vigentes en las percepciones paisajísticas de las comunidades de esta región, vemos que esto no es ni fue así. Lejos de ser erradicados completamente, ciertos paisajes se revitalizan en la actualidad, en tanto 
que otros son cuestionados y olvidados. O dejados ahí, hasta nuevo aviso...

Los paisajes, en ese sentido, deben ser considerados como sujetos a una constante tensión histórica. En los casos observados, la ocupación del territorio ganado por Chile, el paisaje "natural" representaba un desafío o un obstáculo a remontar. Así, la reconfiguración del paisaje fue lograda efectivamente mediante la incorporación de tecnología monumental. Es importante remarcar, por tanto, que la monumentalidad está constituida por una multiplicidad de experiencias de aquellos que habitaron estos espacios y artefactos (algunos más grandes, otros más pequeños) que forman parte de un ensamblaje que va más allá de lo local.

En ese sentido, la arqueología, como el estudio de los restos materiales, nos ofrece una aproximación a estas tensiones o tiene el potencial de exponerlas y visibilizarlas. Será el análisis de esos procesos de monumentalidad (entendida como relacionalidad de la experiencia en torno a lo que será en algún punto definido como monumento), lo que nos permite vislumbrar cómo espacios marginales, como los que aquí se abordan, inciden en la manufactura de un orden e imaginario social: lo moderno. Finalmente, el intricado panorama descrito en este trabajo ilustra aquello que caracteriza a la modernidad como fenómeno global. La modernidad emerge producida por la combinación de procesos globales de escala mundial, como el capitalismo o el conflicto bélico de principios del siglo XX, y sus efectos sobre poblaciones y configuraciones locales (Johnson 1999; Tsing 2015). Por esto, es importante reconocer la necesidad de un análisis de diferentes escalas como lo que aquí se propone para entender mejor su dinámica.

La conclusión a la que arribo en este trabajo enfatiza el papel de una monumentalidad promovida partir de la instauración de maquinarias y tecnología que resulta del análisis de los datos materiales y restos arqueológicos, y se sustentan en las recientes investigaciones acerca de los procesos de chilenización (Aguirre y Mondaca 2011; Díaz et al. 2004, 2016; González 2002, 2009a, 2012). No obstante, es importante notar que -en este punto- este estudio de paisajes históricos arqueológicos no da cuenta de otras escalas menores (por ejemplo: la vida al interior de los campamentos) que es aún un tema pendiente de la arqueología del norte chileno y que, por involucrar un nivel de análisis y metodologías distintas aún en proceso, espera presentarse en otro trabajo. Por tanto, las ideas e interpretaciones aquí planteadas nececitarán ser complementadas con mayores datos documentales más precisos que puedan profundizar, confirmar o rechazar -en parte o su totalidad- estas propuestas.

Agradecimientos: Este trabajo fue elaborado bajo el auspicio de los proyectos: UTA Mayor 3714-14 y el proyecto Anillo SOC 1405: "Cambio climático y variabilidad social a largo Plazo en el desierto de Atacama", que permitieron establecer una visión comparativa de largo plazo. Una versión inicial del mismo fue presentada en el $8^{\circ}$ Congreso de Teoría Arqueológica de América del Sur (TAAS), en el simposio "Paisajes en Conflicto", co-organizado junto a Eduardo Herrera Malatesta. Agradezco a Ian Thomson, Tomás Bradanovic y Pamela Cerda por su introducción a Tacora, y a José Capriles, Marta Crespo, Fernando Castro, Sergio González Bravo, y a los estudiantes del curso de Arqueología Histórica 2015 que participaron en el mapeo y prospección del sitio Jazpampa. Estoy igualmente agradecido a las personas a cargo de la revisión del manuscrito por las observaciones vertidas al mismo, las cuales permitieron clarificar varias ideas dentro del argumento y en particular a Sergio González por sus comentarios precisos y su entusiasta recepción del tema. Angela Macias, una vez más, aportó valiosos comentarios y sugerencias. Todos los errores y omisiones, no obstante, son enteramente míos.

\section{Referencias Citadas}

Acuto, F. 1999. Paisaje y Dominación: la Constitución del Espacio Social en el Imperio Inka. En Sed Non Satiata. Teoría Social en la Arqueología Latinoamericana Contemporánea, editado por A. Zarankin y F. Acuto, pp. 33-75. Del Tridente, Buenos Aires.

Acuto, F. 2005. The materiality of inka domination. Landscape, spectacle, memory, and ancestors. En Global Archaeological Theory. Contextual Voices and Contemporary Thoughts, editado por P. Funari, A. Zarankin y E. Stovel, pp. 211-235.
Kluwer Academic/Plenum Publishers, Springer, New York. Aguirre Munizaga, C. y C. Mondaca 2011. Estado nacional y comunidad andina. disciplinamiento y articulación social en Arica, 1880-1929. Historia 40:5-50. Santiago.

Allen, C.J. 2016. The living ones: Miniatures and animation in the Andes. Journal of Anthropological Research 72:416-441.

Anschuetz, K.F., R.H. Wilshusen y Ch.L. Scheick. 2001. An archaeology of landscapes: Perspectives and directions. Journal of Archaeological Research 9:157-211. 
Anzaldúa, G. 1987. Borderlands. The New Mestiza: La Frontera. 1st ed. Spinsters/Aunt Lute, San Francisco.

Bailey, D. 2005. Prehistoric Figurines. Representation and Corporeality in the Neolithic. Routledge, London.

Bardet, P. 2012. Demarcating territory: Historical markers in the United States. Miranda (Online) 6:1-9. doi:10.4000/ miranda. 2920.

Barnes, T. y G. Feldman 1980. Nationalism, Industrialization, and Democracy, 1815-1914. University Press of America, London.

Barrett, J. y I. Ko 2009. A Phenomenology of Landscape: A Crisis in British Landscape Archaeology? Journal of Social Archaeology 9:275-294.

Bauer, B. 1998. The Sacred Landscape of the Inca: The Cusco Ceque System. University of Texas Press, Austin.

Beaudry, M. y S. Mrozowski 2001. Cultural Space and Worker Identity in the Company City: 19th-Century Lowell, Massachusetts. En The Archaeology of Urban Landscapes: Explorations in Slumland, editado por A. Mayne y T. Murray, pp. 118-131. Cambridge University Press, Cambridge.

Berenguer, J. 2000. Tiwanaku: Los Señores del Lago. Museo Chileno de Arte Precolombino, Santiago.

Bernedo Pinto, P. 1999. Los industriales alemanes de Valdivia, 1850-1914. Historia 32:5-42.

Bittman, B. y G. Alcaide 1984. Historical archaeology in abandoned nitrate 'Oficinas' in Northern Chile: A Preliminary Report. Historical Archaeology 18:52-75.

Boudat Ducollier, L., J.R. Couyoumdjian y M. Gaju de Estellé 1889. Album de las Salitreras. 1ra Ed. Fac. Biblioteca Naciona de Chile, Iquique-Santiago.

Branton, N. 2009. Landscape approaches in historical archaeology: The archaeology of places. International Handbook of Historical Archaeology 51-65.

Bubba Zamora, C. y X. Albo Corrons 2010. John Murra nos ayuda a cargar la responsabilidad de los abuelos y abuelas. Chungara Revista de Antropología Chilena 42:113-125.

Cadiz, F. 2013. La 'chilenización' en el norte y sur de Chile. Una necesaria revisión. Cuadernos Interculturales 11(20):11-43.

Capaldo, A., D. Damm y C. Odone 2010. Sobre el habitar la pampa del Toco (1890-1920). Si Somos Americanos. Revista de Estudios Transfronterizos X (2):175-198.

Cassasas, J.M. 1976. La arqueología histórica en el Norte Grande chileno. En Homenaje al Dr. Gustavo LePaige, S.j., editado por H. Niemeyer, pp. 219-26. Universidad del Norte, Antofagasta.

Childe, G. 1950. The Urban Revolution. Town Planning Review 21 (1):3-17. Liverpool University Press.

Chile-Peru 1929. Treaty between Chile and Peru for the Settlement of the Tacna-Arica Territorial Dispute, with Supplementary Protocol, Lima, 3 June 1929. Treaty Series.

Chile, Academia de Historia 1979. Boletín de La Guerra Del Pacífico 1879-1881. 2nd ed. Editorial Andrés Bello, Santiago.
Clarke, D.L. 1968. Analytical Archaeology. Methuen and Company. Ltd. London, London.

Company, American Sulphur Mining 1871. Some Facts about Sulphur and Sulphur Mining: Also, the Prospectus of the American Sulphur Mining Company ... editado por American Sulphur Mining Company. New Orleans. https://books.google. cl/books?id=L-YQAAAAIAAJ.

Cowie, S. 2011. The Plurality of Power: An Archaeology of Industrial Capitalism. Springer New York.

Darvill, T. 2008. Pathways to a panoramic past: A brief history of landscape archaeology in Europe. En Handbook of Landscape Archaeology, editado por B. David y J. Thomas, pp. 60-77. Left Coast Press, Walnut Creek.

De Vos, B. 1999. El Surgimiento del Paradigma Industrializador en Chile (1875-1900). Dirección de Bibliotecas, Archivos y Museos (DIBAM), Santiago.

DeLanda, M. 2006. A New Philosophy of Society. Assemblage Theory and Social Complexity. Continuum, London.

Deleuze, G. y F. Guattari 1987. A Thousand Plateaus (Trans por B. Massumi). University of Minnesota, Press Minneapolis.

Díaz Araya, A., R. Ruz y C. Mondaca 2004. La administración chilena entre los Aymaras: Resistencia y conflicto en los Andes de Arica (1901-1926). Anthropologica 22 (22):215-235.

Díaz, A., P. Salazar y D. Soto 2016. Los obreros del volcán. indígenas y procesos de transición laboral en las azufreras de Tacora y Taapaca. Norte de Chile (Siglo XX). Estudios Atacameños. Arqueología y Antropología Surandinas 52:69-89.

Domeyko, I. 1850. Memoria sobre la Colonización en Chile. Imp. Julio Belén y Cia., Santiago.

Edmundson, W. 2011. The Nitrate King: A Biography of "Colonel" John Thomas North. Studies of the Americas. Palgrave Macmillan, New York.

Erickson, C. 1999. Neo-enviornmental determinism and agrarian 'collapse' in Andean Prehistory. Antiquity 73 (281):634-642.

Erickson, C. 2006. Intensification, political economy, and the farming community; in defense of a bottom-up perspective of the past. En Agricultural Strategies, editado por J. Marcus y Ch. Stanish, pp. 233-265. Cotsen Institute of Archaeology, University of California, Los Angeles.

Erickson, C. 2009. Agency, causeways, canals, and the landscapes of everyday life in the Bolivian Amazon. En Landscapes of Movement: Trails, Paths, and Roads in Anthropological Perspective, editado por J. Snead, C. Erickson y A. Darling, pp. 204-231. University of Pennsylvania Museum of Archaeology and Anthropology, Philadelphia.

Foucault, M. 1983 [1969]. La Arqueología del Saber. 2a edición. Siglo XXI Editores, México.

Foucault, M. 1986. Of Other Spaces. Diacritics 16 (1):22-27.

Given, M. 2005. Mining landscapes and Colonial rule in EarlyTwentieth-Century Cyprus. Historical Archaeology 39 (3):49-60.

González, H. 1997. apuntes sobre el tema de la identidad cultural en la región de Tarapacá. Estudios Atacameños 13:27-45. 
González, H. y R. Ruz Zagal 2015. Fe en el papel: la inscripción del dominio de las tierras de comunidad en el altiplano chileno. Diálogo Andino 46:143-52.

González, S. 2002. Hombres y Mujeres de la Pampa: Tarapacá en el Ciclo de Expansión del Salitre. LOM, Santiago.

González, S. 2005. La crítica a la máquina surgida durante el ciclo del salitre. Diálogo Andino 25:113-125.

González, S. 2006. Pampa Escrita. Cartas y Fragmentos del Desierto Salitrero de Tarapacá. DIBAM, Santiago.

González, S. 2009a. El Norte Grande de Chile: la definición histórica de sus límites, zonas y líneas de fronteras, y la importancia de las ciudades como geosímbolos fronterizos. Revista de Historia Social y de Las Mentalidades 2 (13):1910-1930. http://www.revistaidea.usach.cl/ojs/index.php/ historiasocial/article/view/98.

González, S. 2009b. El Norte Grande de Chile y sus dos triplefronteras: andina (Perú, Bolivia y Chile) y circumpuneña (Bolivia, Argentina y Chile). Cuadernos Interculturales 7 (13):27-42.

González, S. 2009c. La presencia boliviana en la sociedad del salitre y la nueva definición de la frontera: auge y caída de una dinámica transfronteriza (Tarapacá 1880-1930). Chungara Revista de Antropología Chilena 41:71-81.

González S. 2012 la ressistencia de los tarapaqueños al monopolio salitrero peruano durante el gobierno de Manuel Pardo, desde el estanco a la expropiación (1872-1876). Chungara Revista de Antropología Chilena 44:101-114.

Grimson, A. 2004. Fronteras, naciones y región. Ponencia Presentada en el Foro Social de Las Américas, Quito. http:// www.ibase.org.br/userimages/alejandro_grimson_esp.pdf.

Harvey, D. 2009. Cosmopolitanism and the Geographies of Freedom. Columbia University Press, New York.

Hodder, I. y C. Orton 1976. Spatial Analysis in Archaeology. New Studies in Archaeology. Cambridge University Press, Cambridge.

Janusek, J. 2004. Identity and Power in the Ancient Andes Tiwanaku Cities Through Time. Routledge, London.

Johnson, M. 1994. Ordering houses, creating narratives. En Architecture and Order. Approaches to Social Space, editado por M. Parker Pearson y C. Richards, pp. 153-159. Routledge, London.

Johnson, M. 1999. Historical, archaeology, capitalism. En Historical Archaeologies of Capitalism, editdo por M. Leone y P. Potter, pp. 219-32. Springer, New York

Johnson, M. 2008. Ideas of Landscape. Wiley \& Blackwell, Oxford.

Johnson, M. 2012. Phenomenological approaches in landscape archaeology. Annual Review of Anthropology 41 (1):269-84.

Korpisari, A. y M. Pärssinen 2011. Pariti: The Ceremonial Tiwanaku Pottery from an Island in Lake Titicaca. Academia Scientiarum Fennica, Helsinki.

Lefebre, H. 1991. The Production of Space. Blackwell, Malden.

Macchiavello, S. 1935. Estudio económico sobre la industria del azufre en Chile. Anales de la Facultad de Ciencias Jurídicas y Sociales 1 (1-2). http://www.analesdelderecho.uchile.cl/ index.php/ACJY/article/view/3984/3880.

McGuire, R. 1991. Building power in the cultural landscape of Broome Country, New York 1880 to 1940. En The Archaeology of Inequalit, editado por R. McGuire y R. Paynter, pp. 102-124. Brasil Blackwell Ltda., Oxford.

Moore, J. 1996. Architecture and Power in the Ancient Andes: The Archaeology of Public Buildings. Cambridge University Press, Cambridge.

Orange, H. 2012. Cornish Mining Landscapes: Public Perceptions of Industrial Archaeology in a Post-Industrial Society. PhD Tesis inédita. University College London.

Ortega, L. 1981. Acerca de los orígenes de la industrialización chilena, 1860-1879. Nueva Historia 2:3-54.

Osborne, J. 2014. Approaching Monumentality in Archaeology. SUNY Press, Albany.

Parker Pearson, M. y C. Richards 1994. Architecture and Order. Approaches to Social Space. Routledge, London.

Pérez Rosales, V. 1854. Memoria Sobre Emigración, Inmigración I Colonización. Julio Belin I Ca, Santiago.

Pérez, J. 1893. La Industria Nacional Estudios I. Descripciones de algunas fábricas de Chile. Boletín de La Sociedad de Fomento Fabril 2:3-36.

Pinto, A. 1959. Chile, un Caso de Desarrollo Frustrado. Editorial Universitaria, Santiago

Pinto, J. y L. Ortega 1990. Expansión Minera y Desarrollo Industrial: Un Caso de Crecimiento Asociado (Chile, 18501914). Universidad de Santiago, Santiago.

Ponce Sanjines, C. 1969. Tunupa y Ekako. Estudio Arqueológico Acerca de Las Efigies Precolombinas de Dorso Adunco. Academia Nacional de Ciencias de Bolivia, La Paz.

Rees, Ch., C. Silva y F. Vilches 2007. Haciendo visible lo invisible. Asentamientos salitreros en la periferia del cantón El Toco, II Región. Actas del XVIII Congreso de Arqueología Chilena, pp.???, entidad editora?, ciudad?

Rubertone, P. 1989. Landscape as artifact: Comments on the archaeological use of landscape treatment in social, economic and ideological analysis. Historical Archaeology 23 (1):50-54.

Rudolph, W. 1952. Sulphur in Chile. Geographical Review 42 (4):562-590

Rueschemeyer, D., E. Stephens y J. Stephens 1992. Capitalist Development and Democracy. University of Chicago Press, Chicago.

Sarwana, S A. 1969. Economic considerations in boundary making. Pakistan Horizon 22 (3):221-237.

Silverman, H. y W. Isbell 2002. Andean Archaeology II: Art, Landscape, and Society. Springer, New York.

Soto, A. 1998. Influencia Británica en el Salitre. Origen, Naturaleza y Decadencia. Universidad de Santiago, Santiago. 
Staller, J. 2008. Pre-Columbian Landscapes of Creation and Origin. Springer, New York.

Thomas, J. 2001. Archaeologies of Place and Landscape. En Archaeological Theory Today, editado por I. Hodder, pp. 165186. Polity Press, Cambridge.

Thomson, I. 2009. La industria azufrera y el ferrocarril de tacora, el más alto del mundo. Instituto Ferroviario. Arica -Santiago. http://www.institutoferroviario.cl/2013/01/la-industria-azufreray-el-ferrocarril-de-tacora-el-mas-alto-en-el-mundo/.

Tilley, Ch. 1994. A Phenomenology of Landscape : Places, Paths and Monuments. Explorations in Anthropology. Berg, Oxford.

Tsing, A.L. 2015. The Mushroom at the End of the World: On the Possibility of Life in Capitalist Ruins. Princeton University Press, Princeton?

Troncoso, A. 2006. Arquitectura del paisaje y relacionalidad del espacio. En Puentes Hacia el Pasado: Reflexiones Teóricas en
Arqueología, editado por D. Jackson, D. Salazar y A. Troncoso, pp. 192-204. Sociedad Chilena de Arqueología, Santiago.

Véliz, C. 1963. La mesa de tres patas. Desarrollo Económico 3:231-247.

Vilches, F. y H. Morales 2016. From herders to wage laborers and back again: Engaging with capitalism in the Atacama Puna Region of Northern Chile. International Journal of Historical Archaeology 1-20.

Vilches, F., Ch. Rees y C. Silvia 2008. Arqueología de asentamientos salitreros en la Región de Antofagasta (18801930): Síntesis y perspectivas. Chungara Revista de Antropología Chilena 40:19-30.

Vitry, Ch. 2003. Control territorial a través de puestos de observación y peaje en el Camino del Inca. Tramo MorohuasiIncahuasi, Salta - Argentina. Cuad. Fac. Humanid. Cienc. Soc., Nac, Jujuy 20:151-172.

\section{Notas}

1 La propuesta crítica de análisis de paisajes arqueológicos, entendida como arqueología de paisajes (landscape archaeology), surge como una necesidad de desmarcarse de los estudios de espacialidad de la geografía económica, y la lógica cartesiana modernista implícita en la conceptualización de sitio arqueológico y los estudios de análisis espacial (Clarke 1968; Hodder y Orton 1976). Apoyada en la geografía humana, la arqueología (posprocesual) de paisajes se enfoca en las relaciones sociales y culturales, política y relaciones de poder, aspectos relacionados a la identidad y la experiencia (Thomas 2001:166).

2 En su trabajo en torno a la extensa red de canales y terraplenes que conforman los paisajes prehispánicos de las tierras bajas de Bolivia, Erickson (2009:206) argumenta que el tamaño y monumentalidad de los trabajos de tierra estarían más bien relacionados a la escala e intensidad de interacción de sus sociedades. Esta propuesta no niega la existencia de jerarquías sociales sino que, contrariamente a otros planteamientos, no considera que estas manifestaciones monumentales sean dependientes de estructuras jerárquicas para su construcción o existencia.

Claramente influenciada por una perspectiva fenomenológica, la propuesta de González $(2005,2009,2011)$ resuena con la corriente de análisis de la arqueología de paisajes y sostiene el argumento que aquí se plantea.

En su obra "Arqueología del Saber", Michel Foucault (1969) plantea que la construcción discursiva se produce, al igual que en los procesos geológicos, a partir de la sedimentación de ciertas ideas que van conformando los estratos base sobre las que las narrativas históricas se asientan.

5 Ubicado en el alineamiento volcánico de la Cordillera de Los Andes, el Volcán Tacora constituye uno de los puntos de actividad relacionadas a la minería de azufre cuyas características están siendo recientemente relevadas arqueológicamente en otros lugares (Vilches y Morales 2016; Vilches et al. 2014).

6 De acuerdo al Decreto 17-11-2015, el Complejo Industrial Azufrero Tacora (CIAT), comprende 3 sectores: (1) Villa Industrial, el nodo de conexión ferroviaria; (2) Aguas Calientes, el poblado situado a los pies del Tacora, y (3) el denominado sector de montaña y andariveles. Para este análisis, estas áreas se presentan ligeramente modificadas; esto se debe a que responden a un ordenamiento previo por parte del investigador ya que el trabajo de campo fue realizado antes de la emisión del mencionado decreto.

8 La concesión de territorios a inversionistas diversos, formaba parte de las estrategias de control estatales mediante el discurso de fomento a la producción industrial (Díaz et al. 2016) y -por consiguiente- la modernización de este espacio geográfico, buscando así otorgarle una identidad territorial nueva como parte de Chile. De acuerdo a González y Ruz, la tenencia colectiva de tierra había sido oficialmente inscrita en Tacna, en 1913, y empleada exitósamente en un juicio interpuesto contra un comerciante de origen italiano (es decir, validada legalmente) (González y Ruz 2015:1478). Sin embargo, a pesar de estos intentos e iniciativas de mantener la titulación comunitaria como un "mecanismo de defensa corporativo" el estado rápidamente pasó a privilegiar la tenencia individual por parte de sus habitantes: "En las inscripciones de títulos de dominio en los registros chilenos de la propiedad, la comunidad no tiene cabida como una juridica de tipo corporativo -cuyo prototipo histórico es la comunidad colonial- podrá someter los derechos de propiedad individuales" (González y Ruz 2015:150).

9 Es importante notar la distinción que autores de la época (e incluso posteriormente) realizan entre obreros chilenos e indígenas (implicando la condición foránea de estos últimos); este es un punto importante al que voy a referirme nuevamente más abajo.

10 El caso del volcán Chupiquiña y su azufrera habría sido un caso similar pero nos limitamos a hablar solo del Tacora ya que el primero no jjjjj relevado en terreno y, por esta razón, 1 no fue incluido en este trabajo.

Jazpampa, el nombre de la oficina, aparece en algunas publicaciones como Jaspampa. Para mantener coherencia, en este trabajo utilizaré la grafía inicial.

12 A inicios de 1980, los trabajos de Alcaide (1983; cf. Cassasas 1976) y la síntesis de Bittmann y Alcaide (1984), llaman la atención respecto de la necesidad de incorporar una mirada hacia el pasado histórico por parte de la disciplina arqueológica. Subsecuentemente, diferentes trabajos de exploración de impacto ambiental relacionados principalmente al avance masivo de la modernidad que mantuvo a este tipo de sitios en peligro de ser impactados por 
el desarrollo de nuevas industrias o proyectos de desarrollo confirmaron la importancia de los mismos (Capaldo et al. 2010; Rees et al. 2007; cf. Vilches et al. 2008).

13 Agradezco a uno de los revisores la provocativa pregunta respecto del efecto mágico de las máquinas. Si bien el término mágicamente quizás no sea aceptado como parte de una propuesta seria, tengo la impresión de que es precisamente el que mejor describe el proceso nacionalizador y de configuración identitaria que se produce a través de la
14 inclusion de estas nuevas tecnologías.

El concepto de "geosímbolos" fue introducido originalmente por el geógrafo Bonnemaison (1981) quién, enmarcado en el estructuralismo y la Nueva Geografía, definió a los geosímbolos como: "un lugar, una extensión o un accidente geográfico que por razones políticas, religiosas o culturales revisten a los ojos de ciertos pueblos o grupos sociales una dimensión simbólica que refuerza su identidad" (Bonnemaison 1981:256). 